AnnMarie Mallat MD, * Joseph Roberson MD, $\dagger$ John G. Brock-Utne MD*

\title{
Preoperative marijuana inhalation - an airway concern
}

\begin{abstract}
Purpose: Cannabis Sativa (marijuana) may cause a variety of respiratory disorders including uvular oedema. This case illustrates that uvular oedema secondary to marijuana inhalation may cause a potentially serious postoperative clinical problem.

Clinical features: A healthy 17-yr-old man who inhaled marijuana prior to general anaesthesia. In the recovery room, after an uneventful general anaesthetic, acute uvular oedema resulted in post operative airway obstruction and admission to hospital. The uvular oedema was treated successfully with dexamethasone.

Conclusion: Recent inhalation of marijuana before general anaesthesia may cause acute uvular oedema and post operative airway obstruction. The uvular oedema can be easily diagnosed and treated.
\end{abstract}

Objectif: Le cannabis sativa (marijuana) peut provoquer plusieurs problèmes respiratoires dont l'oedème de la luette. Cette observation montre que l'oedème de la luette secondaire à l'inhalation de marijuana peut être à l'origine d'un problème clinique postopératoire grave.

Caractéristiques cliniques: Un jeune homme de 17 ans ayant inhalé depuis peu de la marijuana subit une anesthésie gênérale. À la salle de réveil, après une anesthésie générale

\section{Key words}

ABUSE: marijuana;

AIRWAY: obstruction;

ANAESTHESIA: postoperative;

COMPLICATIONS: Uvular oedema;

PHARMACOLOGY: dexamethasone, marijuana.

From the *Anesthesia Department, H3580, Stanford University Medical Center, Stanford, CA $94305-5115$ and †California Ear Institute at Stanford, 801 Welch Road, Palo Alto, CA 94304.

Address correspondence to: Dr. John G. Brock-Utne, Anesthesia Department, H3580, Stanford University Medical Center, Stanford, CA 94305-5115.

Accepted for publication 7th March, 1996. sans incident, un oedème de la luette provoque une obstruction des voies respiratoires et son admission à l'hôpital. L'oedème se dissipe avec le dexométhasone.

Conclusion: L'inhalation récente de marijuana avant une anesthésie générale peut provoquer un oedème aigu de la luette avec obstruction des voies respiratoires. Cette affection est facile à diagnostiquer et à traiter.

The clinical effects produced when inhaling the various products of the plant Cannabis Sativa (CS) (marijuana) are mainly concentrated on the behavioural and psychological effects that a person experiences.1 However, CS may cause respiratory disorders, including bronchitis, asthma, uvular oedema and oropharyngitis. ${ }^{1-3}$ This report describes the development of severe uvular oedema requiring admission to the hospital after an uneventful general anaesthetic in a 17-yr-old healthy man with a history of preoperative marijuana smoking.

\section{Case history}

A 17-year-old, $70 \mathrm{~kg}$ man (ASA I), with chronic otitis media was scheduled for a tympanomastoidectomy and placement of a pressure equalization tube in the left ear. His history was unremarkable, except that he occasionally took antihistamines for nasal congestion, and had inhaled marijuana on a weekly basis, for at least six to eight months. On the day of surgery, he exhibited a flattened affect, i.e., very little response to placement of the intravenous catheter, appeared unusually calm thereby giving rise to a suspicion of marijuana use early that morning. However, we did not question him about our suspicion since his mother was with him. Physical examination was notable for an unsymptomatic reddened class I airway with enlarged tonsils and uvula. No evidence of infection was seen in the pharynx, nor of any lymph node enlargement in the head and neck. The patient was afebrile with a normal white cell count (7000) and haemoglobin (14 mg\%). Since we were not sure if he had smoked marijuana prior to admission, we elected not to give any prophylactic treatment such as steroids or antihistamines. An iv line was established, and midazolam ( $1 \mathrm{mg}$ ) iv was given before arrival in the 
operating room. Routine monitors (ECG, ${ }^{*}$ noninvasive blood pressure monitor, $\dagger$ oxygen saturation probe $\ddagger$ ) were placed, and after preoxy-genation, an uneventful induction of anaesthesia with $(100 \mu \mathrm{g})$ fentanyl , $(1 \mathrm{mg})$ midazolam, and $(200 \mathrm{mg}$ ) propofol ensued. Tracheal intubation was facilitated atraumatically with vecuronium (7 mg), but enlarged red tonsils and a red pharynx were again noted. The uvula was elongated, but not excessively (approximately $3 \mathrm{~cm}$ ). Anaesthesia was maintained with oxygen/isoflurane/vecuronium and morphine. The duration of the operation was two and a quarter hours after which the patient's pharynx was gently suctioned and the endotracheal tube removed while the patient was awake.

In the recovery room, the patient was comfortable, afebrile, and vital signs were stable. He fell asleep, but despite supplemental oxygen $\left(3 \mathrm{~L} \cdot \mathrm{min}^{-1}\right)$ via a nasal cannula, the oxygen saturation decreased to $90 \%$. The patient was awakened and oxygen saturation improved to $100 \%$. He complained of having "something lodged in his throat," which he felt he was unable to relieve by coughing. On examination of his pharynx, an even larger and swollen, elongated uvula was noted. The tip of the uvula could not be seen. The patient description indicated that the tip was sitting on or very near the glottic opening. Flexible fibreoptic laryngoscopy was performed in the recovery room and revealed normal vocal cord motion and arytenoid location. The size of the uvula was deemed to be $10-12 \mathrm{~cm}$ (J.R.). No oedema of the epiglottis or hypopharynx was present. Dexamethasone $10 \mathrm{mg}$ iv was administered and the patient informed that he would be admitted to hospital for observation and continuous oxygen saturation monitoring. On leaving the recovery room; approximately three hours later, the oxygen saturation was $98 \%$ while breathing supplemental oxygen via the nasal cannula ( 3 $\left.L \cdot \min ^{-1}\right)$. No pathogen sample for a possible infectious process was obtained because the etiology of the uvular oedema was considered mainly to be due to his recent marijuana inhalation, combined with our atraumatic airway manipulation. However, if dexamethasone had not had the desired effect, racemic epinephrine would have been attempted. Furthermore, samples for throat pathogens would have been taken and antibiotics administered.

He made an uneventful recovery and was discharged from the hospital the following morning with an improvement in symptoms, a marked decrease in the

\footnotetext{
*Hewlett Packard. Mountain View, CA 94041. †Dynamap, Critikon, Johnson \& Johnson. Tampa, FL 33634. $\ddagger$ Nellcor. Hayward, CA 94545 .
}

uvular swelling (4-5 cm), and an oxygen saturation of $100 \%$ breathing room air. No antibiotics were given. On further questioning, he admitted to having smoked marijuana four to six hours before admission to our preoperative area. Since the patient made a dramatic improvement, we did not request permission for specific urine or blood toxicology studies.

\section{Discussion}

Isolated uvular oedema secondary to marijuana use has not been reported in the anaesthetic literature. We presume that the aetiology of the postoperative airway obstruction and resulting decreased oxygen saturation were due to the excessively enlarged uvula obstructing the glottic opening. The differential diagnosis for uvular oedema include allergies (e.g., latex and drugs), trauma (e.g., secondary to tracheal intubation, suctioning or uvular entrapment, infection and familiar angioneurotic oedema. All these diagnoses were considered by our ENT colleague, who was convinced that this was due to marijuana inhalation, having previously seen a similar case in an emergency room.

According to Guariscio, ${ }^{3}$ isolated uvulitis is defined as an inflammation confined to or originating in the uvula, and is apparently a disease of low incidence. Only 16 cases have been reported in the literature over the last $20 \mathrm{yr}^{3}{ }^{3}$ The most common cause of isolated uvulitis (uvular oedema) is bacterial infection and trauma following the use of instruments in the airway. In a study ${ }^{1}$ of 31 young men who smoked an enormous quantity (>100 g) of marijuana for several months, 12 complained of persistent recurrent rhinopharyngitis. The authors noted that in these 12 patients, the uvular oedema developed acutely after heavy use, and lasted 12-24 hr. Unfortunately, in that study the exact numbers of individuals developing uvula swelling was not specified and only a brief mention was made of this physical finding. Marijuana burns at a higher temperature than tobacco, and therefore is claimed to be more irritant to mucous membranes. ${ }^{2}$ In the study by Sloan, ${ }^{4}$ three adolescents with negative throat cultures, developed acute inflammation of the uvula following heavy use of marijuana. In the Guarisco study, ${ }^{3}$ all patients had inhaled large quantities of marijuana, six to twelve hours before onset of respiratory symptoms, none had evidence of infections.

Steroids exert their effects by increasing capillary endotracheal permeability, thus leading to decreased mucosal oedema. Furthermore by stabilizing lysosomal membranes, they decrease the inflammatory reaction. Dexamethasone's relative anti-inflammatory potency is 25 times greater than that of hydrocortisone and it has a long half-life of 36 to $72 \mathrm{hr}$. It is claimed that steroids 
take at least three hours to produce any substantial physiological change, while dexamethasone should be even faster. In patients with acute laryngotracheobronchitis, dexamethasone appears also to decrease the severity of symptoms and decrease the need for racemic epinephrine treatments. ${ }^{5}$

Steroids have been shown to bring about dramatic relief in patients with post-traumatic uvulitis. ${ }^{6-9}$ Hawkins has recommended dexamethasone "Decadron" in the management of these cases with good effect. ${ }^{10} \mathrm{~A}$ dose of $12 \mathrm{mg}$ should not be exceeded. ${ }^{10}$ Patients with non-infectious uvulitis and without airway compromise may benefit from out-patient treatment with a short course of oral steroids. ${ }^{9}$ Theoretically, steroids could also benefit patients with uvulitis secondary to an inhalation irritant like marijuana, as demonstrated in this case. The rapid recovery in this case is mainly thought to be due to the injection of the dexamethasone.

Two authors ${ }^{6,8}$ have used diphenhydramine to treat postanaesthetic uvular oedema. The rationale for this treatment is the possibility that the uvular oedema is an allergic drug reaction. Based on current data, the routine use of diphenhydramine cannot be recommended. However, if there is strong evidence of an allergic reaction and/or angioneurotic-oedema, treatment should be with parenteral epinephrine, steroids and diphenhydramine.

We conclude that marijuana induced uvular oedema is a potentially serious post-operative clinical problem that is potentially easy to diagnose and treat. Despite this, we feel that in patients for elective surgical procedures, with an acute history of marijuana exposure, surgery should be cancelled since prophylactic treatment may not be efficient.

\section{References}

1 Tennant FS Jr, Preble M, Prendergast TJ, Ventry P. Medical manifestations associated with hashish. JAMA 1971; 216: 1965-9.

2 Schwartz $R$. Uvular edema and erythema (Letter). Pediatr Infect Dis J 1984; 3: 187.

3 Guarisco JL, Cheney ML, LeJeune FE Jr, Reed HT. Isolated uvulitis secondary to marijuana use. Laryngoscope 1988; 98: 1309-10.

4 Sloan MP. On uvulitis from smoking marijuana (Letter). Pediatric Notes 1985; 9: 56.

5 Ravindran $R$, Priddy $S$. Uvular edema, a rare complication of endotracheal intubation (Letter). Anesthesiology 1978; 48: 374.

6 Seigne TD, Felske A, DelGiudice PA. Uvular edema (Letter). Anesthesiology 1978; 49: 375-6.

7 Shulman MS. Uvular edema without endotracheal intubation (Letter). Anesthesiology 1981; 55: 82-3.

8 Haselby $K A$, McNiece WL. Respiratory obstruction from uvular edema in a pediatric patient. Anesth Analg 1983; 62: 1127-8.

9 Hawkins $D B$, Crockett $D M$, Shum TK. Corticosteroids in airway management. Otolaryn Head Neck Surg 1983; 91 : 593-6.

10 Cressman WR, Myer CM. Diagnosis and management of croup and epiglottis. Pediatr Clin North Am 1984; 41: 265-76. 